\title{
DE LAS SOCIEDADES CHINCHORRO AL PRESENTE. UN ENFOQUE DE CIENCIA Y TECNOLOGÍA EN EDUCACIÓN DE MUSEO
}

\author{
FROM CHINCHORRO COMMUNITIES TO THE PRESENT. A SCIENTIFIC AND \\ TECHNOLOGICAL APPROACH IN MUSEUM EDUCATION
}

\author{
Julia Córdova-González*, Yanko Ossandón**, Nancy Álvarez*** y Jorge Bernal****
}

\begin{abstract}
La interpretación de los contenidos del museo arqueológico por el público que lo visita se basa principalmente en los conocimientos previos del espectador y en los textos informativos de las exposiciones, pues la ayuda personal que ofrece el museo, diseñada para el visitante individualizado, no puede ser permanente. La limitación de espacios destinados a la interpretación textual de vitrina, las soluciones museográficas elegidas para satisfacer las necesidades de los visitantes, tanto como los contenidos de las cédulas explicativas, rara vez pueden abarcar las variadas expectativas del amplio espectro intelectual de los visitantes del museo así como sus requerimientos biofísicos. Como una respuesta a esas limitaciones se diseñó el software de educación de museo llamado Yatiqasiña. El presente artículo menciona la estructura de trabajo de este instrumento y reporta los resultados de una evaluación cuantitativa reciente en una muestra estratificada de usuarios de Arica sobre actitud, conocimientos y valores aportados por el software. Este es un avance de un proceso evaluativo experimental que incluye cinco ciudades de Chile.

Palabras claves: Educación de museo, Museo Arqueológico San Miguel de Azapa, Cultura Chinchorro, evaluación de software.

The interpretation of the archaeological past as presented in museum displays is based on the visitor's previous information and the supporting texts provided by the museum, since personal help tailored to the visitor's needs cannot be permanently at hand. The necessarily limited spaces for textual information, graphic solutions, as well as label contents can seldom answer individual queries within the vast spectrum of visitors and their expectations. Moreover, biophysical requirements of some museum users may not be satisfied. A strategic approach to partially overcome these limitations was undertaken through Yatiqasiña, software of museum education. This article briefly describes its propositional structure, and reports the results of a recent evaluation of the beta product on attitude, contents, and values, in a stratified sample of users in Arica chosen from the educational stratum. This paper is a partial report of an experimental study including four other cities in Chile.
\end{abstract}

Key words: Museum education, Archaeological Museum San Miguel of Azapa, Chinchorro Culture, software evaluation.

Una de las misiones más importantes del museo arqueológico en la conservación de bienes culturales es la interpretación científica de esos bienes que constituyen patrimonio colectivo para la nación que los resguarda. En el mismo nivel de importancia está la misión educativa, que consiste en traducir el lenguaje críptico de las ciencias en expresiones comprensibles, dirigidas a un público no especializado en el tema y, así, transformar el interés que los visitantes tienen por ver y conocer los contextos culturales en actividades conectadas, comprometidas e integradoras capaces de provocar el crecimiento personal (Hein 1998: 3).

Los acuerdos internacionales sobre los principios que rigen las excavaciones arqueológicas, la propiedad del patrimonio cultural y su uso se refieren a la responsabilidad del museo en su resguardo, investigación y difusión a través de exposiciones y programas educativos (UNESCO 1956: Art. 10 al 12). La práctica profesional de acreditación de los museos que cumplen su objetivo como organizaciones sociales, establecida en los países

\footnotetext{
* Departamento de Arqueología y Museología, Universidad de Tarapacá, Arica, Chile. jcordova@uta.cl

** Departamento de Computación e Informática, Universidad de Tarapacá, Arica, Chile. yossando@uta.cl

*** Departamento de Filosofía y Psicología, Universidad de Tarapacá, Arica, Chile. nalvarez@uta.cl

**** Departamento de Economía y Finanzas, Universidad de Tarapacá, Arica, Chile. jbernal@uta.cl
} 
desarrollados, se ajusta a los requisitos mínimos establecidos por el Consejo Internacional de $\mathrm{Mu}-$ seos (ICOM), y dice que "To be eligible for accreditation, an institution must be organized, permanent, nonprofit, and essentially educational or esthetic in purpose" (AAM 1990: 19). ICOM define el museo como "una institución permanente, sin fines de lucro, al servicio de la sociedad y de su desarrollo, abierta al público, que adquiere, conserva, investiga, difunde y expone los testimonios materiales del hombre y su entorno para la educación y el deleite del público que lo visita" (ICOM 1995: Art. 2,1). En esta definición la preposición "para" proporciona la finalidad de todo el enorme esfuerzo humano, intelectual, afectivo, material y económico, que envuelve la preocupación del patrimonio cultural. Basándose en esta misión fundamental del museo como institución social, se han desarrollado en los últimos años numerosos y variados programas de investigación para identificar el perfil de los visitantes del museo, tipologías y patrones de visita, estructuras cognoscitivas aplicadas. Se han diseñado ensayos metodológicos; estrategias para descubrir la manera cómo es que los visitantes del museo se educan; se han evaluado los programas experimentales, y se ha establecido la rutina de evaluaciones permanentes, formativas y globales. Sobre esta práctica se ha desarrollado una epistemología para el pensamiento reflexivo y se han creado paradigmas metodológicos para estímulo y discusión profesional (ver entre otros Falk y Dierking 1992, 1995; Fyfe y Ross 1996; Hein 1998, Hein y Alexander 1998; Hooper-Greenhill 1988a y b, 1991, 1992, 1994a y b, 1997, 1999a y b, 2000, Hooper-Greenhill y Moussouri 2000; Roberts 1997).

La incorporación de actividades educativas en el museo, principalmente a partir de los años 1970, transformó las exposiciones estáticas, basadas en el paradigma literario, en actividades dinámicas de diálogo, de interacción, de reflexión y descubrimiento, utilizando los conocimientos previos del visitante y las estrategias de aprendizaje significativo, estimulado por un entorno social favorable (ver, por ejemplo, Merriman 1989a y b).

No obstante que la educación es crucial como función del museo desde el momento que recibe público no especializado en las temáticas que difunde, las actividades sistemáticas de educación en museos generalmente se ven limitadas por el nú- mero de profesionales comprometidos en forma permanente para desarrollar esta responsabilidad. La demanda siempre supera la disponibilidad de recursos humanos calificados en este campo. Como una respuesta a esta demanda se diseñó el software Yatiqasiñ $a^{2}$, para ser aplicado en el Museo Arqueológico San Miguel de Azapa (MASMA), perteneciente a la Universidad de Tarapacá, Arica, Chile. Aunque no abarca todas las proposiciones culturales del Museo, es un recurso disponible las veinticuatro horas del día.

Yatiqasiña es una voz aymara que no tiene sinonimia en español pero su referente semasiológico se ajusta a la idea de construir un nuevo conocimiento a partir de la percepción de un objeto parcialmente conocido, vinculándolo con la experiencia y el saber que el espectador ya posee (Mamani 1995). Al elegir esta voz para titular la herramienta museológica se consideró su valor semántico, pero también su concordancia con el modelo constructivista de aprendizaje que se emplea como metodología educativa. Además, se deseaba representar en la población aymara chilena todas aquellas culturas prehispánicas que atesora el MASMA y cuyo dominio lingüístico desconocemos.

La amplitud temporal de las colecciones del MASMA abarca ca.10.000 años de historia prehispánica regional, de modo que no era posible construir un software con múltiples ambientes de trabajo para cada período cultural identificable con una profundidad media en el breve tiempo del desarrollo experimental. Todavía más, se tiene una limitación técnica, la recuperación de imágenes en contextos ricos en detalle y color es lenta, principalmente para los recursos computacionales disponibles en el museo. Considerando lo anterior, se optó por seleccionar solamente el registro cultural más antiguo, correspondiente a las sociedades Chinchorro, muy desconocido en el ámbito nacional e internacional ${ }^{3}$ a pesar de la enorme implicancia que tiene para el conocimiento del desarrollo social de culturas prístinas en todo el mundo. Yatiqasiña sería una proposición ejemplar en el caso de ser evaluada positivamente. El software tiene la capacidad de ser usado en otros museos así como en colegios, centros culturales y, parcialmente ${ }^{4}$, en la red universal Internet.

La investigación antropológica física desarrollada en el Departamento de Arqueología y Museología de la Universidad de Tarapacá es la base de información científica para textos e ilus- 
traciones (Allison et al. 1984; Arriaza 1995; Standen 1997, entre otros). Del mismo modo, los referentes arqueológicos toman fuentes como Focacci (1974), Dauelsberg (1974), Muñoz y Chacama (1982, 1993), Schiappacasse y Niemeyer (1984); los antecedentes medio ambientales llevan a Vilaxa y Corrales (1993), Crom (1993), IFOP s/r; tejidos a Ulloa $(1974,1982)$. Las ilustraciones y colecciones Chinchorro son las producidas en este Departamento.

Se diseñó un software verdaderamente interactivo, donde el usuario no solamente define una ruta de lectura u observación, sino que participa en ambientes de trabajo produciendo su propio diseño interpretativo, que puede revisar y corregir en la medida que logra mayores conocimientos. Como la intención es motivar a un amplio rango de usuarios, el software utiliza también los recursos de multimedios del computador, involucrando los sentidos y la imaginación. La variedad de ambientes de trabajo tiene como objetivo atraer una o varias de las inteligencias que pueden encontrarse entre los visitantes del museo (Gardner 1995).

Yatiqasiña ofrece ambientes de instrucción a través de la visita electrónica del museo y sus vitrinas documentadas; también instruye con textos complementarios, ilustrados e interlazados que lleva al lector a información no detallada en la sala de exhibición del MASMA, como es el hábitat propio de aquellas sociedades, sus condiciones de salud, viviendas, y permite acceder a enunciados científicos en la dirección determinada por el usuario. Se ofrece referencias bibliográficas para profundizar conocimientos y un correo electrónico para conectarse con los especialistas del museo real. Ofrece ambientes de construcción de conocimiento apoyados en una base de datos de objetos arqueológicos que permite seleccionar objetos, describirlos, compararlos, desarrollar una ficha técnica o analítica y redactar resúmenes sobre los hallazgos. Este trabajo se puede guardar como un archivo personal al cual se puede regresar para modificarlo o ampliarlo cuando se posean mayores conocimientos. En una línea recreativa, Yatiqasiña presenta ambientes de juegos que tienen como objetivo reforzar el aprendizaje. En un ambiente creativo se presenta la opción de redactar un cuento ilustrado, teniendo la oportunidad de dar forma a una interpretación de ese pasado remoto basada en los conocimientos y valores adquiridos.
Con el objeto de evaluar esta herramienta educativa, se aplicó una primera versión en el MASMA en el año 1998 en una población escolar estadísticamente significativa. Los resultados fueron decididamente alentadores, lo que llevó a desear contrastar Yatiqasiña en ambientes socioculturales distintos al original. Fue así como se generó un segundo proyecto ${ }^{5}$ para verificar el grado de validez que pudiera alcanzar en lugares distantes geográfica y demográficamente. Se eligieron ciudades de extremo en el país: Punta Arenas y Arica; de centro-sur y centro-norte: Temuco y La Serena respectivamente; y una del centro continental: Valparaíso. Los informes finales para cada ciudad serán publicados como artículos en distintas publicaciones periódicas idealmente editadas en el museo o localidad respectiva (Córdova-González et al. 2000, 2000a, b y c). El informe final de Arica corresponde al presente artículo.

Completado el periplo de evaluación en las cuatro ciudades extrarregionales, se volvió a contrastar la experiencia en Arica usando la misma metodología y variables de evaluación que se emplearon en esas ciudades, esto es, actitud hacia el software y el museo real; contenidos y valores aportados por Yatiqasiña en una versión mejorada.

\section{Administración del Software}

Tomando en consideración que los estudiantes de Arica, en su gran mayoría, han visitado el MASMA, se instaló el software en el laboratorio de computación del Liceo Integrado Eduardo Frei Montalva. Se eligió este establecimiento por contar con un equipamiento computacional acorde a los requerimientos técnicos de Yatiqasiña, contar con la amable colaboración de la Dirección, Jefe de Laboratorio, y la de la profesora a cargo de la Unidad Técnica que coordinó esta actividad. Además, por tratarse de un liceo integrado podía proporcionar la muestra estudiantil de enseñanza básica y media, determinada con validez estadística. El laboratorio cuenta con 19 computadores en red, vinculado al programa Enlaces del Ministerio de Educación.

La configuración de la red interna del laboratorio presentó algunas dificultades para la instalación del software, por cuanto su arquitectura obliga a utilizar el software NetClass disponible en esa unidad, de modo que esta actividad tuvo un retraso en el tiempo de carga de cada equipo que no se 
había presentado en ninguno de los otros colegios visitados. Una vez instalado Yatiqasiña, la aplicación del producto no presentó inconvenientes y se desarrolló según el programa previsto. La experiencia se realizó entre los días 24 al 28 de julio y 22 de agosto del año 2000. El material educativo quedó instalado en el laboratorio, a disposición de alumnos y profesores para su posterior utilización en las diversas asignaturas para las cuales Yatiqasiña es relevante.

\section{Metodología}

Del amplio espectro de visitantes del MASMA, se eligió el segmento estudiantil para evaluar Yatiqasiña. La selección consideró que este segmento está conformado por grupos muy homogéneos entre los cuales se pueden hacer comparaciones; los estudiantes son fáciles de contactar a través de la estructura organizacional, argumento válido cuando se trabaja con un gran número de participantes. Además, se producen puntos de complementación y encuentro, de acuerdo a los objetivos fundamentales transversales de la educación chilena, requeridos tanto para el desarrollo de conceptos antropológicos como cognitivos relacionados (Magendzo et al. 1997). Consecuentemente, existe interés de un número importante de profesores por tener una vinculación más estrecha con el Museo; el software es un facilitador de encuentros.

Aun cuando el MASMA cuenta con una red de computadores para ser utilizados en sus salas de exhibición y educativa, más la evidente riqueza de sus colecciones, la aplicación se programó en un establecimiento educacional distante del museo, a fin de permitir la comparación de datos entre las ciudades que se incorporaron en el proyecto de investigación, considerando que en otras regiones la mayoría de los museos no dispone de equipamiento computacional suficiente para uso simultáneo de 10 personas por lo menos. No obstante lo anterior, en todos los casos, se solicitó a los profesores de los cursos que participarían en la evaluación llevar a sus alumnos al museo antes de la aplicación del programa, como una manera de refrescar conocimientos y experiencias. Para determinar el tamaño de la población de referencia se utilizó la información de la matrícula escolar de cuatro cursos de enseñanza regular: $4^{\circ}$ y $8^{\circ}$ años de enseñanza básica, y $1^{\circ}$ y $4^{\circ}$ años de enseñanza me- dia, de la comuna de Arica. Esta información fue proporcionada por la Dirección Provincial de Educación de Arica y Parinacota.

Se determinó para el estudio realizar un muestreo estratificado proporcional con un error muestral de un 5\% y un $95 \%$ de confianza. El análisis de estratos determinó un tamaño muestral de 272 estudiantes, cuya composición corresponde a 71 alumnos de $4^{\circ}$ año básico, 62 de $8^{\circ}$ año básico, 72 de $1^{\text {er. }}$ año medio y 67 de $4^{\circ}$ año de enseñanza media.

El instrumento de medición consistió en tres cuestionarios, de actitud, de conocimientos, y de apreciación y valores, que previamente fueron validados por grupos de expertos, y, mediante un estudio exploratorio, aplicado a estudiantes de educación básica y media.

Para el análisis de datos se empleó el software de ciencias sociales SPSS 9.0. En el análisis de actitud se usó la prueba t en la contrastación de variables dicotómicas, Museo Virtual (Yatiqasiña) y Museo Real (MASMA), y en las comparaciones por sexo. La prueba Scheffé se usó en el test profiláctico de variables múltiples, específicamente en la determinación de la significación estadística de actitud hacia ambos museos entre los distintos niveles de escolaridad. Se tomó como criterio eliminar aquellos instrumentos que presentaron cuatro o más ítemes sin responder, lo que determinó una diferencia del $\mathrm{N}$ entre los datos del test de actitud y los tests de conocimiento y apreciación y valores (Figura 1).

\section{Resultados}

\section{a) Encuesta de actitud}

Las comparaciones entre los puntajes totales obtenidos en el instrumento de actitud hacia el museo virtual y real indican que existen diferencias altamente significativas entre ambos $(\mathrm{t}=-4,419 ; \alpha=0,000)$, siendo la actitud hacia el museo virtual más favorable que hacia el museo real (Tabla 1).

Al hacer la comparación por niveles de escolaridad (Tabla 1), notamos que la aplicación de los instrumentos de evaluación hacia el museo virtual y real no arrojó diferencias significativas en los niveles de $4^{\circ}$ año de enseñanza básica y $4^{\circ}$ año de enseñanza media, es decir, la actitud de los alum- 
Test de Actitud
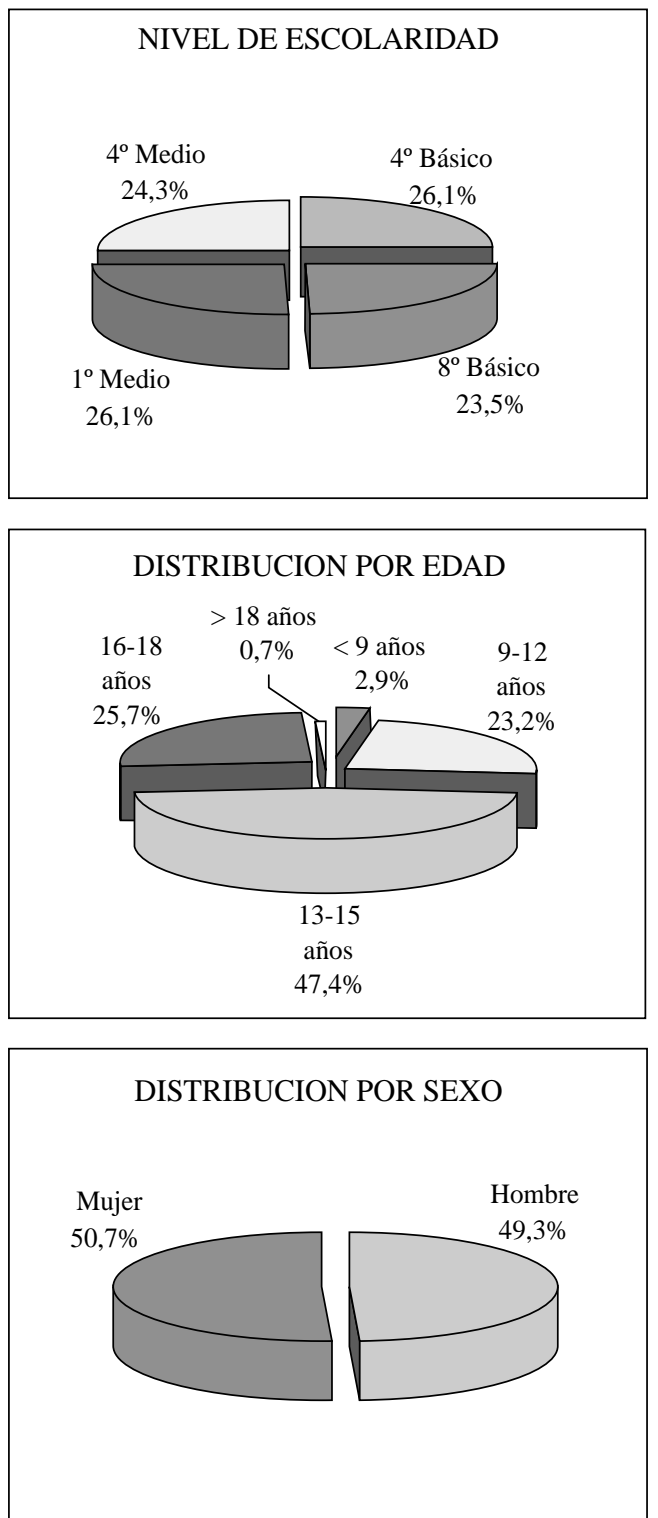

Figura 1. Distribución tamaño muestral.

Sample size distribution.

nos de estos niveles hacia cualquiera de los museos es similar. Sí se aprecian diferencias significativas al efectuar las comparaciones en el nivel de $8^{\circ}$ año de enseñanza básica $(\mathrm{t}=-4,130 ; \alpha=0,000)$ y $1^{\text {er. }}$ año de enseñanza media $(\mathrm{t}=-3,983 ; \alpha=$ $0,000)$. Por otra parte los puntajes entre ambos instrumentos se muestran altos y significativamente correlacionados en los niveles de $8^{\circ}$ año básico y $1^{\text {er. }}$ año medio $(r=0,429$ y $r=0,473 ; \alpha=0,000$ en
Encuesta de Conocimientos y Valores
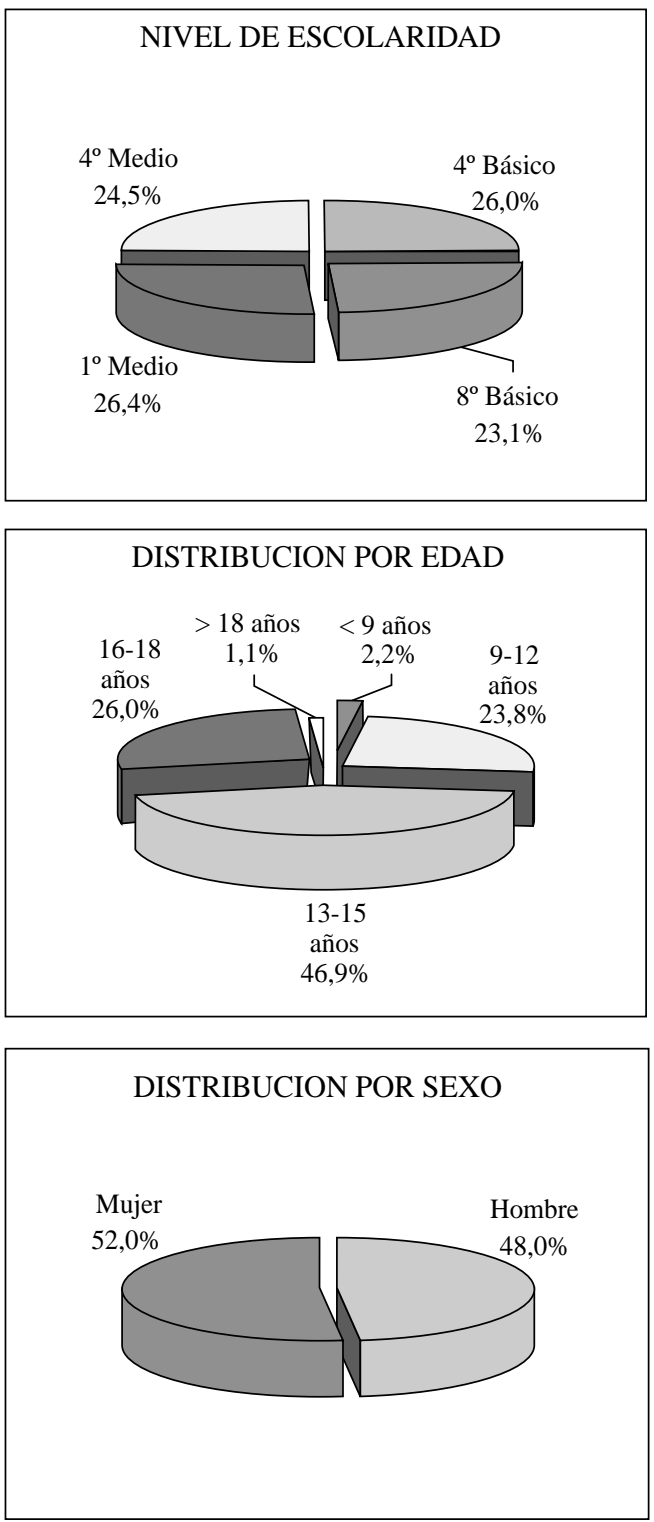

ambos casos), no así en $4^{\circ}$ año básico. Para $1^{\text {er. año }}$ medio también se da dicha correlación $(\mathrm{r}=0,624$, $\alpha=0,000$ ).

En las comparaciones por los rangos por edad, el análisis entre las medias de actitud obtenidas hacia el museo virtual y hacia el museo real en alumnos de 9-12 años y de 16-18 años no resultan significativas. Las diferencias sólo son significativas en el rango de edad de 13-15 años $(t=-4,717$; 
Tabla 1. Estadísticos descriptivos y comparativos de la actitud hacia el museo virtual y real en la muestra total y según nivel de escolaridad, sexo y edad en la ciudad de Arica.

Comparative descriptive statistics categories of the attitude towards the virtual and actual museum of the total sample, according to educational level, sex and age in the city of Arica.

\begin{tabular}{|c|c|c|c|c|c|c|}
\hline \multirow[b]{2}{*}{ Variable } & \multicolumn{2}{|c|}{ Museo Virtual (Yatiqasiña) } & \multicolumn{2}{|c|}{ Museo Real } & \multicolumn{2}{|c|}{ Análisis comparativo } \\
\hline & Promedio & $\begin{array}{l}\text { Desviación } \\
\text { estándar }\end{array}$ & Promedio & $\begin{array}{c}\text { Desviación } \\
\text { estándar }\end{array}$ & $\mathrm{T}$ & $\mathrm{P}$ \\
\hline Muestra total & 77,1647 & 22,7973 & 83,9839 & 23,3171 & $-4,419 * *$ & 0,000 \\
\hline \multicolumn{7}{|c|}{ Nivel de escolaridad } \\
\hline $4^{\circ}$ básico & 74,6034 & 15,8024 & 79,2931 & 23,5700 & $-1,361$ & 0,179 \\
\hline $8^{\circ}$ básico & 70,3651 & 20,8430 & 81,7937 & 20,2462 & $-4,130$ & $0,000 * *$ \\
\hline $1^{\circ}$ medio & 72,9077 & 25,0398 & 86,1231 & 26,9899 & $-3,983$ & $0,000 * *$ \\
\hline $4^{\circ}$ medio & 90,7143 & 22,5606 & 88,2857 & 21,2856 & 1,012 & 0,315 \\
\hline \multicolumn{7}{|l|}{ Rangos de edad } \\
\hline Menos de 9 años & 73,000 & 17,4547 & 79,2857 & 19,8806 & Sin análisis & $\mathrm{N}=7$ \\
\hline Entre 9-12 años & 74,8235 & 15,7387 & 79,2941 & 24,2052 & $-1,204$ & 0,243 \\
\hline Entre $13-15$ años & 73,7295 & 24,4189 & 84,3033 & 24,2129 & $-4,717$ & $0,000 * *$ \\
\hline Entre 16-18 años & 85,2985 & 22,4729 & 87,3284 & 20,4075 & $-0,779$ & 0,439 \\
\hline Más de 18 años & 88,500 & $\mathrm{~N}=2$ & 88,500 & $\mathrm{~N}=2$ & Sin análisis & $\mathrm{N}=2$ \\
\hline \multicolumn{7}{|l|}{ Sexo } \\
\hline Mujeres & 72,4328 & 19,2062 & 80,9846 & 22,2439 & \multicolumn{2}{|c|}{ Diferencias Museo Virtual } \\
\hline & & & & & $-3,544$ & $0,000 * *$ \\
\hline \multirow[t]{2}{*}{ Hombres } & 82,2481 & 25,3852 & 87.4274 & 23,9804 & \multicolumn{2}{|c|}{ Diferencias Museo Real } \\
\hline & & & & & $-2,221$ & $0,027 *$ \\
\hline
\end{tabular}

* Diferencia significativa.

** Diferencia altamente significativa.

$\alpha=0,000)$, lo que sería coincidente con la pertenencia de estos alumnos a $8^{\circ}$ año básico y $1^{\circ}$ año medio.

En la comparación por sexo, se observan diferencias significativas entre hombres y mujeres con relación al puntaje obtenido en el instrumento de evaluación de la actitud hacia el museo virtual $(\mathrm{t}=$ $-3,544 ; \alpha=0,000)$, siendo más favorable la actitud de las alumnas que la de los alumnos.

Un resultado similar se aprecia también con respecto al museo real, obteniendo las mujeres un puntaje que indica una actitud más positiva hacia el museo real que los hombres, siendo estas dife- rencias estadísticamente significativas $(\mathrm{t}=-2,221$; $\alpha=0,027)$.

En cuanto a las comparaciones al interior de las medidas de actitud hacia el museo real y virtual en función del nivel de escolaridad (Tabla 1) encontramos diferencias significativas sólo en el museo virtual $(\mathrm{F}=14,333, \mathrm{gl}=3, \alpha=0,000)$. $\mathrm{La}$ prueba de Scheffé señala que estos resultados se deben a las diferencias estadísticamente significativas que presenta el $4^{\circ}$ año medio con relación a todos los otros niveles de escolaridad (Tabla 2), siendo la actitud de los alumnos de este nivel la menos favorable. 
Tabla 2. Comparaciones múltiples usando la prueba de Scheffé.

Multiple comparisons by the Scheffé's test.

\begin{tabular}{|c|c|c|c|c|c|c|c|}
\hline \multirow[b]{2}{*}{ Dependent Variable } & \multirow[b]{2}{*}{ (I) curso } & \multirow[b]{2}{*}{ (J) curso } & \multirow[b]{2}{*}{$\begin{array}{c}\text { Mean } \\
\text { Difference } \\
(\mathrm{I}-\mathrm{J})\end{array}$} & \multirow[b]{2}{*}{ Std. Error } & \multirow[b]{2}{*}{ Sig. } & \multicolumn{2}{|c|}{$\begin{array}{l}\text { 95\% Confidence } \\
\text { Interval }\end{array}$} \\
\hline & & & & & & $\begin{array}{l}\text { Lower } \\
\text { Bound }\end{array}$ & $\begin{array}{l}\text { Upper } \\
\text { Bound }\end{array}$ \\
\hline \multirow[t]{4}{*}{$\begin{array}{l}\text { Puntaje Total en el } \\
\text { Museo Virtual }\end{array}$} & $4^{\circ}$ básico & $\begin{array}{l}8^{\circ} \text { básico } \\
1^{\circ} \text { medio } \\
4^{\circ} \text { medio }\end{array}$ & $\begin{array}{c}4,3082 \\
1,6005 \\
-17,6625^{*}\end{array}$ & $\begin{array}{l}3,7626 \\
3,7064 \\
3,7338\end{array}$ & $\begin{array}{l}, 727 \\
, 980 \\
, 000\end{array}$ & $\begin{array}{r}-6,2797 \\
-8,8293 \\
-28,1692\end{array}$ & $\begin{array}{l}14,8960 \\
12,0302 \\
-7,1557\end{array}$ \\
\hline & $8^{\circ}$ básico & $\begin{array}{l}4^{\circ} \text { básico } \\
1^{\circ} \text { medio } \\
4^{\circ} \text { medio }\end{array}$ & $\begin{array}{c}-4,3082 \\
-2,7077 \\
-21,9706^{*}\end{array}$ & $\begin{array}{l}3,7626 \\
3,7212 \\
3,7485\end{array}$ & $\begin{array}{l}, 727 \\
, 912 \\
, 000\end{array}$ & $\begin{array}{l}-14,8960 \\
-13,1791 \\
-32,5186\end{array}$ & $\begin{array}{r}6,2797 \\
7,7636 \\
-11,4226\end{array}$ \\
\hline & $1^{\circ}$ medio & $\begin{array}{l}4^{\circ} \text { básico } \\
8^{\circ} \text { básico } \\
4^{\circ} \text { medio }\end{array}$ & $\begin{array}{c}-1,6005 \\
2,7077 \\
-19,2629 *\end{array}$ & $\begin{array}{l}3,7064 \\
3,7212 \\
3,6921\end{array}$ & $\begin{array}{l}, 980 \\
, 912 \\
, 000\end{array}$ & $\begin{array}{r}-12,0302 \\
-7,7636 \\
-29,6522\end{array}$ & $\begin{array}{r}8,8293 \\
13,1791 \\
-8,8736\end{array}$ \\
\hline & $4^{\circ}$ medio & $\begin{array}{l}4^{\circ} \text { básico } \\
8^{\circ} \text { básico } \\
1^{\circ} \text { medio }\end{array}$ & $\begin{array}{l}17,6625 * \\
21,9706 * \\
19,2629 *\end{array}$ & $\begin{array}{l}3,7338 \\
3,7485 \\
3,6921\end{array}$ & $\begin{array}{l}, 000 \\
, 000 \\
, 000\end{array}$ & $\begin{array}{r}7,1557 \\
11,4226 \\
8,8736\end{array}$ & $\begin{array}{l}28,1692 \\
32,5186 \\
29,6522\end{array}$ \\
\hline \multirow[t]{4}{*}{$\begin{array}{l}\text { Puntaje Total en el } \\
\text { Museo Real }\end{array}$} & $4^{\circ}$ básico & $\begin{array}{l}8^{\circ} \text { básico } \\
1^{\circ} \text { medio } \\
4^{\circ} \text { medio }\end{array}$ & $\begin{array}{l}-1,3346 \\
-5,3022 \\
-7,8267\end{array}$ & $\begin{array}{l}4,1705 \\
4,1088 \\
4,1705\end{array}$ & $\begin{array}{l}, 992 \\
, 645 \\
, 320\end{array}$ & $\begin{array}{l}-13,0731 \\
-16,8670 \\
-19,5652\end{array}$ & $\begin{array}{r}10,4038 \\
6,2626 \\
3,9118\end{array}$ \\
\hline & 8 básico & $\begin{array}{l}4^{\mathrm{o}} \text { básico } \\
1^{\mathrm{o}} \text { medio } \\
4^{\mathrm{o}} \text { medio }\end{array}$ & $\begin{array}{r}1,3346 \\
-3,9675 \\
-6,4921\end{array}$ & $\begin{array}{l}4,1705 \\
4,0745 \\
4,1367\end{array}$ & $\begin{array}{l}, 992 \\
, 814 \\
, 483\end{array}$ & $\begin{array}{l}-10,4038 \\
-15,4359 \\
-18,1355\end{array}$ & $\begin{array}{r}13,0731 \\
7,5008 \\
5,1513\end{array}$ \\
\hline & $1^{\circ}$ medio & $\begin{array}{l}4^{\circ} \text { básico } \\
8^{\circ} \text { básico } \\
4^{\circ} \text { medio }\end{array}$ & $\begin{array}{r}5,3022 \\
3,9675 \\
-2,5245\end{array}$ & $\begin{array}{l}4,1088 \\
4,0745 \\
4,0745\end{array}$ & $\begin{array}{l}, 645 \\
, 814 \\
, 943\end{array}$ & $\begin{array}{r}-6,2626 \\
-7,5008 \\
-13,9928\end{array}$ & $\begin{array}{r}16,8670 \\
15,4359 \\
8,9438\end{array}$ \\
\hline & $4^{\circ}$ medio & $\begin{array}{l}4^{\circ} \text { básico } \\
8^{\circ} \text { básico } \\
1^{\circ} \text { medio }\end{array}$ & $\begin{array}{l}7,8267 \\
6,4921 \\
2,5245\end{array}$ & $\begin{array}{l}4,1705 \\
4,1367 \\
4,0745\end{array}$ & $\begin{array}{l}, 320 \\
, 483 \\
, 943\end{array}$ & $\begin{array}{l}-3,9118 \\
-5,1513 \\
-8,9438\end{array}$ & $\begin{array}{l}19,5652 \\
18,1355 \\
13,9928\end{array}$ \\
\hline
\end{tabular}

* The mean difference is significant at the .05 level.

\section{b) Encuesta de conocimientos}

Para la pregunta de conocimientos se prepararon ilustraciones por tema: objetos, adornos y vestimenta, actividades y tradiciones funerarias.

Para la pregunta de identificación de objetos se presentaron ocho ilustraciones en total, cinco de ellas correspondían efectivamente a la cultura Chinchorro. En esta medición los alumnos de $4^{\circ}$ año básico mostraron mayor conocimiento, respondiendo en forma correcta en un total de 65,32\%. Con respecto a los estudiantes de $4^{\circ}$ año medio sólo el 57,65\% respondió correctamente esta pregunta, siendo el nivel de menor resultado positivo. Dados los buenos resultados obtenidos se puede concluir que, en general, los estudiantes de Arica logran identificar correctamente los objetos de la cultura Chinchorro (Figura 2).

Con respecto a la identificación de adornos y vestimentas se presentaron tres imágenes correctas de las seis propuestas. Los estudiantes de primer año de enseñanza media obtuvieron el mejor resultado con un $62,27 \%$. Cabe destacar que todos los niveles educacionales objeto de estudio respondieron sobre el promedio de 50\%, observándose el porcentaje más bajo en los alumnos de $4^{\circ}$ 


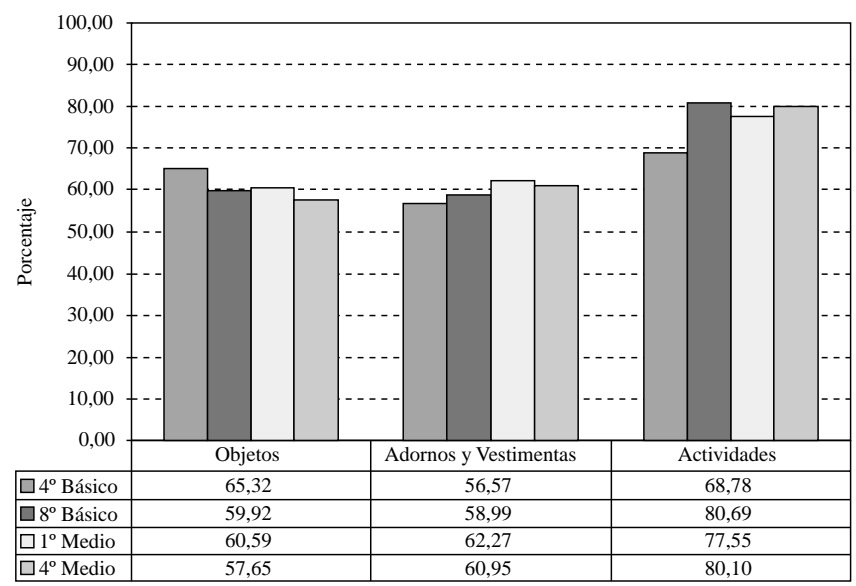

Figura 2. Porcentaje de identificación correcta de objetos, adornos y vestimentas, y actividades.

Percentage of accurate identification of objects, adornments, clothes, and activities.

año básico con un 56,27\%. En general, se puede concluir que los estudiantes de Arica identifican correctamente los adornos y vestimentas de la cultura Chinchorro (Figura 2).

En lo referente a las actividades que realizaban las sociedades Chinchorro, todos los estudiantes de Arica lograron identificarlas correctamente en un porcentaje superior al $65 \%$, obteniendo mejor resultado los estudiantes de octavo básico con un $80,69 \%$, seguido de los estudiantes de $4^{\circ}$ año medio con un $80,10 \%, 1^{\circ}$ medio con un $77,55 \%$ y el menor porcentaje de respuestas correctas es el $4^{\circ}$ año básico con un $68,78 \%$. La medición consideró seis imágenes de diversas actividades, siendo tres de ellas propias de las sociedades Chinchorro (Figura 2).

De igual manera, se obtuvieron resultados muy positivos en lo que se refiere a cómo los Chinchorro enterraban a sus muertos, dado que los porcentajes de respuestas correctas fluctúan entre el $53,52 \%$ obtenido por el cuarto año de enseñanza básica y $86,11 \%$, obtenido por el primer año de enseñanza media. Es decir, todos los niveles educacionales en estudio de la ciudad de Arica identificaron correctamente que los Chinchorro enterraban a sus muertos tendidos de espalda (Figura 3).

En lo que respecta a la identificación del sector donde se desarrolló la cultura Chinchorro en un mapa de Chile, los resultados fueron medianamente satisfactorios, dado que sólo cinco estudiantes identificaron correctamente el área geográfica donde se desarrollaron las sociedades Chinchorro
(I y II Región); sin embargo, si se considera a aquellos que identificaron exclusivamente a la ciudad de Arica los porcentajes fluctúan entre 59\% en cuarto año de enseñanza básica y $92 \%$ en primer año de enseñanza media. Se puede concluir que ningún curso logró reconocer correctamente el amplio sector geográfico donde se manifestó la cultura Chinchorro, identificando sólo el área de sitio tipo.

Con respecto al reconocimiento del tiempo en que vivieron las sociedades Chinchorro, el promedio de todos los participantes en el proceso de evaluación en Arica es de 32,43\%, siendo el primer año de enseñanza media el que presenta un mejor porcentaje de respuestas correctas con un $36,11 \%$ y el octavo año de enseñanza básica es el de menor resultado positivo con un $25,40 \%$. Con lo cual se puede concluir que en general los estudiantes de Arica no logran identificar correctamente el tiempo en que vivieron estas sociedades (Figura 3).

\section{c) Encuesta de apreciación y valores}

Ante la pregunta de si algunos objetos usados por las culturas arcaicas que ellos conocen, todavía se usan, los estudiantes de Arica mencionaron mayoritariamente que el encendedor de madera nunca se usa. Reconocieron continuidad de uso del cintillo para la cabeza en un 45,63\%. Igualmente, ellos reconocieron el uso prolongado de los anzuelos para pescar $(68,80 \%)$, y estimaron que rara vez se usa la pintura en el cuerpo. 


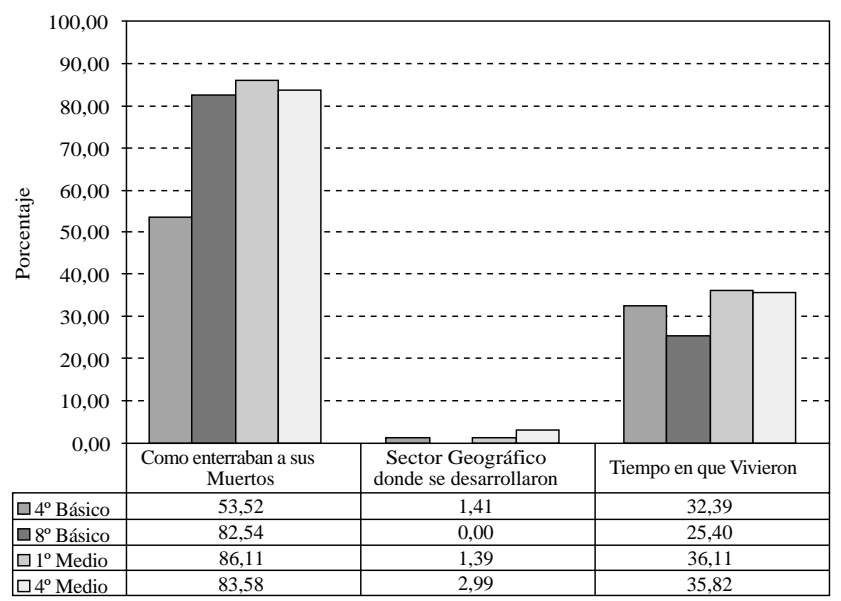

Figura 3. Porcentaje de identificación correcta de tradición funeraria, localización geográfica y temporal de poblaciones Chinchorro.

Percentage of accurate identification of funerary tradition, geographic and temporal localization of Chinchorro populations.

En su mayoría (40,24\%), los estudiantes de Arica de todos los niveles consideraron que la cultura Chinchorro se parece sólo un poco a las culturas más conocidas de la región. Frente a la pregunta sobre la significación que tiene el conocer la cultura Chinchorro, $64 \%$ de los estudiantes de Arica argumentaron que ha sido significativo, porque no imaginaban la existencia en Chile de una cultura tan antigua, porque aumentaron sus conocimientos sobre las distintas culturas de Chile y aprendieron que las momias artificiales más antiguas del mundo están en nuestro país. En oposición, $36 \%$ de los estudiantes de Arica consideraron que no fue significativo el conocer acerca de la cultura Chinchorro, dando como razón principal que la conocían previamente, que no tiene relación con sus vidas y por otras razones que no profundizaron.

Se preguntó a los estudiantes si les parece que el conocer más sobre las culturas antiguas les sirve para comprender mejor lo que es el pueblo chileno, las respuestas reflejaron resultados distintos entre los cuatro niveles (ver Tabla 3). De acuerdo a los datos de esta Tabla, se puede observar que los estudiantes de cuarto año de enseñanza básica y cuarto año de enseñanza media consideran que el conocer más sobre culturas antiguas les permite comprender mejor lo que es el pueblo chileno. No obstante, para los cursos de octavo básico y primero medio no se puede concluir afirmativa o negativamente referente a este punto al no existir una tendencia marcada que sea significativa.
Se preguntó a los estudiantes si consideraban que existían algunas culturas más importantes que otras. $78 \%$ de ellos concordaron que sí había culturas más importantes que otras; justificaron su parecer, sobre la base de la gran cantidad de personas que la forman, las técnicas que han desarrollado, el tiempo que han permanecido y que han sido bases para el desarrollo de otras culturas. El 22\% restante consideró que todas las culturas son igualmente importantes, argumentan que todas las culturas tienen igual valor no importando el tamaño del grupo; que todas las personas son dignas de respeto no importando los bienes que posean; que no todas las culturas tienen las mismas necesidades, y que la conquista de tierras y la dominación de otros pueblos no reflejan siempre mejores modos de vida.

Tabla 3. Percepción de incidencia de las culturas antiguas en la formación de la identidad.

Perception and incidence of ancient indigenous cultures in identity construction.

\begin{tabular}{lccc}
\hline Curso & Mucho & Poco & Nada \\
\hline $4^{\circ}$ año básico & $29,03 \%$ & $35,48 \%$ & $35,48 \%$ \\
$8^{\circ}$ año básico & $13,56 \%$ & $42,37 \%$ & $44,07 \%$ \\
$1^{\text {er. año medio }}$ & $12,50 \%$ & $48,44 \%$ & $39,06 \%$ \\
$4^{\circ}$ año medio & $34,43 \%$ & $34,43 \%$ & $31,15 \%$ \\
\hline
\end{tabular}




\section{Discusión}

Este estudio de carácter cuantitativo nos permite generalizar los resultados en poblaciones estudiantiles similares, pero no nos ofrece la posibilidad de profundizar en las diferencias. Por ejemplo, por qué las mujeres y no los hombres tienen una actitud más favorable hacia el museo virtual; podríamos esperar una actitud semejante en ambos sexos pero se produce esta diferencia. El caso se repite en relación con el museo real. Es evidente que se requiere de una investigación de carácter cualitativo para triangular los datos y acercarnos a una explicación más comprensiva del hecho.

Las comparaciones entre los puntajes totales obtenidos en el instrumento de actitud hacia el museo virtual y real indican que existen diferencias altamente significativas entre ambas, siendo la actitud hacia el museo virtual más favorable que la actitud hacia el museo real. De acuerdo a las comparaciones múltiples de Scheffé la actitud del cuarto medio hacia el museo virtual resulta ser la menos favorable. Se estima que hay varias posibles explicaciones para esta preferencia, entre ellas, la novedad del producto, la posibilidad de interacción en la temática arqueológica siempre atractiva pero distante, la posibilidad de autodirección en el foco de atención dentro del macroambiente de Yatiqasiña, de autorregulación del tiempo destinado a cada subambiente de trabajo. En contraste, la observación empírica de la Educadora de Museo reporta que las visitas al MASMA como parte de un proceso de enseñanza conforme al currículum escolar provocan un alto grado de insatisfacción para los estudiantes; las causales más elocuentes se pueden resumir en el desajuste del tiempo destinado a la visita; el excesivo número de alumnos por salida en relación con las condiciones físicas del museo; falta de motivación, planificación y objetivos para cada visita; insuficiente número de educadores de museo para satisfacer la demanda. Se estima que en grupos escolares de 50 a 60 alumnos solamente un $20 \%$ se beneficia incorporando un conocimiento activo, el restante $80 \%$ tiene una experiencia tangencial, de visión de objetos en el mejor de los casos, pero con pérdida de los contenidos y los valores culturales del museo arqueológico. En tales circunstancias no es de extrañar la preferencia marcada hacia el museo virtual. No obstante, esto se hace evidente fundamentalmente en octavo básico y primero medio. Esto podría explicar por qué los alumnos de estos niveles podrían poseer un mejor nivel de interacción con el computador y por qué la modalidad de interacción con el software pudiera resultar más atractiva para ellos.

En relación con la encuesta de conocimiento debemos establecer la dificultad de esta medición; por muy comprensivo que sea el test siempre quedarán muchas variables fuera de medición porque los conocimientos se multiplican de manera exponencial, sobre todo cuando existe un bagaje amplio de conocimientos previos. Los conocimientos no están determinados solamente por edad ni por niveles escolares, sino por las circunstancias sociales y las opciones de vida (Davidson 1992; Vygotsky 1978). Puesto que Yatiqasiña utiliza mayormente el impacto visual para la transmisión de conocimientos (Figura 4), la medición también ocupó la memoria visual. Los resultados fueron favorables con la excepción del tiempo en que se desarrollaron las sociedades Chinchorro y la extensión del área que habitaron. La explicación de esta situación puede estar en la divergencia de tablas de medición temporal que provoca confusión en quienes no están habituadas a su uso: calendario de uso occidental cristiano, el que incluye fechados anteriores al nacimiento de Cristo y el que fija el presente para fechas arqueológicas. Este punto no será discutido aquí. En cuanto a la dificultad de identificación de distribución geográfica de los rasgos Chinchorro, cabe destacar que el sitio tipo de esta cultura se encuentra en un área de la ciudad de Arica, por lo tanto la identificación toponímica pudo conducir a la confusión en el reconocimiento de la amplitud geográfica de los hallazgos.

La encuesta de conocimiento incluyó también una de apreciación y valores, puesto que en un museo arqueológico todas las evidencias culturales tienen un referente social directo, los conocimientos que aquí se adquieren no pueden estar desvinculados de los grupos humanos que los originaron. Las preguntas en esta sección tendieron a dar una forma de reflexión sobre aspectos que no están directamente enfocados en las exposiciones ni en el software, ni son normalmente temas de discusión en la sala de clases. Para facilitar la reflexión de los alumnos y la tabulación de los datos, se ofrecieron alternativas de respuestas, por esta razón los resultados reportan porcentajes de opiniones semejantes en el amplio número de estu- 


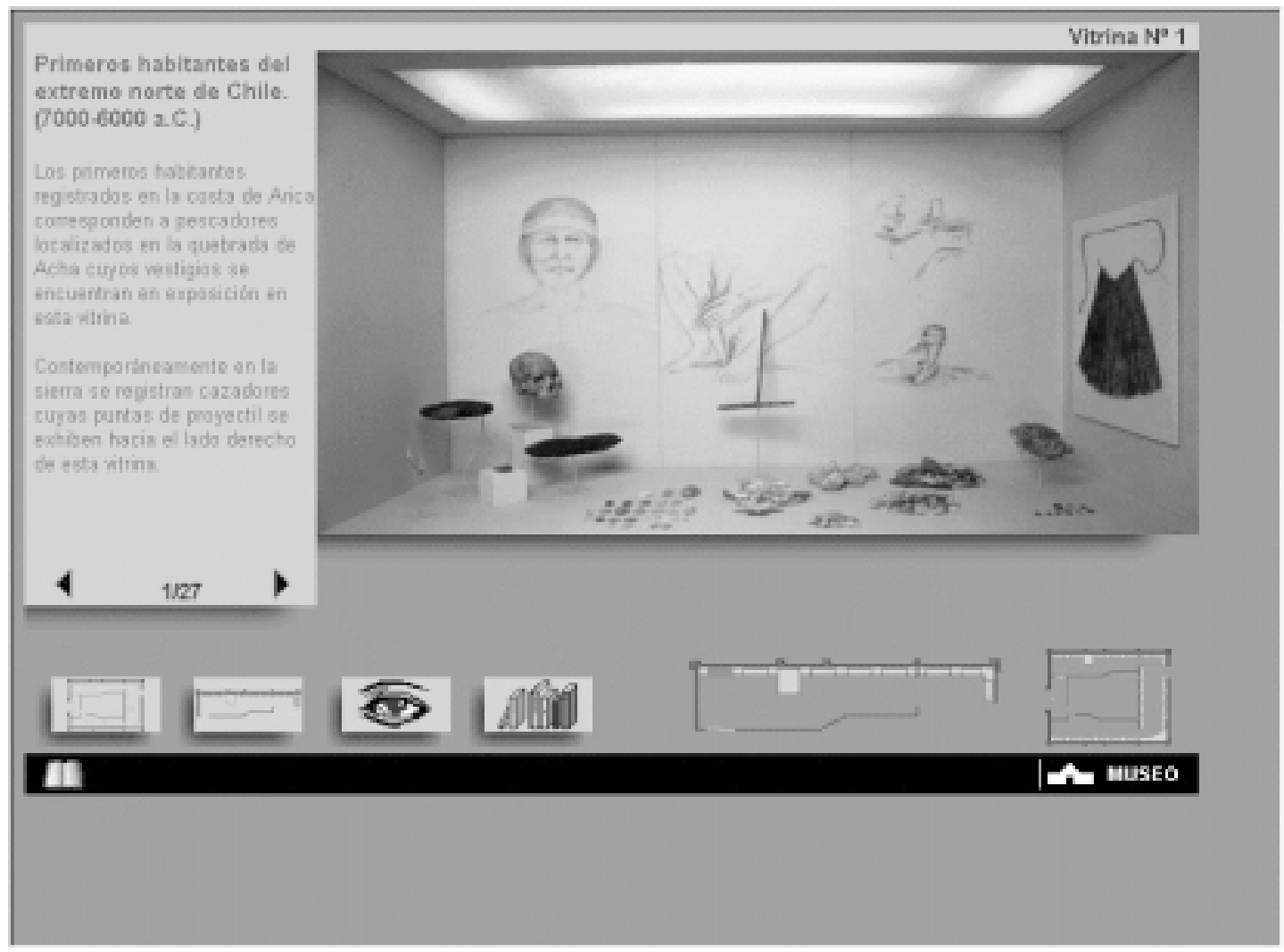

Figura 4. Vitrina $N^{\circ} 1$. Museo Arqueológico San Miguel de Azapa, Arica, Chile. Display Case $N^{o}$ 1. Archaeological Museum San Miguel of Azapa, Arica, Chile.

diantes encuestados, pero se dejó una opción de respuesta abierta para quienes no se identificaban con las alternativas presentadas. Nadie usó esta opción. Al igual que en el caso del test de actitud, en apreciación y valores una investigación cualitativa reportaría resultados más ajustados y descriptivos que los que aporta la investigación cuantitativa, pero esta opción no formaba parte del presente proyecto de investigación. En el segmento de apreciación, vinculando las culturas antiguas con las actuales, se pudo comprobar cierta incapacidad de autoobservación o superficialidad en la observación de semejanza de rasgos en culturas tan distantes unas de otras, sobre todo en lo que respecta a la pintura corporal. Los alumnos estimaron que la pintura en el cuerpo rara vez se usa, en circunstancias que hoy, más que nunca, se repite la práctica, aun cuando en la actualidad los mensajes de la pintura corporal son posiblemente muy distintos.

$\mathrm{El}$ alto porcentaje de estudiantes que estimó que existen culturas más importantes que otras da cuenta del patrón cultural que existe en Chile desde la época colonial española y quizá también precolonial. Desde la iniciación de la República, todas las Constituciones que han regido en el país han declarado la igualdad entre los ciudadanos (Valencia 1951: 83, 116, 155, 175, 216, 349), no obstante, a modo de ejemplo, el sistema educacional por largo tiempo prohibió el uso de las lenguas nativas. La práctica se repite en muchos otros aspectos. La apreciación de las culturas nativas en los museos arqueológicos, etnográficos y de arte, cuando éste es inclusivo, es la mejor opción para modificar concepciones discriminatorias en cualquier ámbito de expresión cultural.

\section{Conclusiones}

El conocimiento de la sociedad Chinchorro, de hecho difícil para un observador de la ciudad, habitante del siglo veintiuno, no podrá ser nunca tan cercano que produzca una percepción inter- 
subjetiva. Una condición para interpretar una cultura es que se encuentren elementos que sean suficientemente parecidos a los empleados por el observador. Dice Davidson (1992: 161) que para que las personas se comuniquen cada una de ellas ha de hablar a la otra y ser entendido por ella, condición imposible en distancias temporales milenarias. Lo que nos queda es la interpretación de hechos y producciones pertenecientes a tales culturas. En este museo la interpretación primaria de las colecciones corresponde a arqueólogos y antropólogos; de esas fuentes procede la organización de exposiciones que tiene como fin la divulgación de la investigación sobre las evidencias culturales, es lo que Lyotard (1994: 51) llama la pragmática del saber científico. La aparición del educador de museo en la escena museológica, de manera sostenida a partir de los años 70, se relaciona con esa pragmática desde la concepción clásica del saber: investigación y enseñanza, pues se requiere encontrar los lenguajes que permitan a los usuarios del museo decodificar los mensajes de la ciencia y comprenderlos, más allá del simple trasvase de información y su absorción como verdades irrefutables. Las salas de exposición del museo tienen como objetivo la comunicación de la investigación; sirve a este objetivo conocer todos los segmentos y ramales de los modelos comunicacionales así como las condiciones, capacidades y oportunidades de los receptores.

En esta investigación se enfocó un sector específico de usuarios del museo; esto no significa que la recepción de los otros segmentos de usuarios no tenga importancia, pero eso será materia de otros proyectos. El acercamiento masivo al conocimiento de sociedades tan distantes del presente como chinchorro, necesariamente requiere de enfoques multidisciplinarios que incorporen todas las fuentes y los medios que conduzcan al objetivo. El ablandamiento de las fronteras disciplinarias, característico de la era postmoderna, facilita el diálogo entre expertos en beneficio de la humanización de la ciencia, asimismo los productos generados tienen un rango de efectividad multiplicado. $\mathrm{Al}$ concluir la segunda fase del proyecto Yatiqasiña así lo entendemos.

Por otra parte, a partir de los resultados obtenidos, se estima que el uso del computador para difundir la investigación arqueológica y provocar el pensamiento reflexivo es una herramienta eficaz para el aprendizaje de contenidos arqueoló- gicos y no alejará a los visitantes del museo; por el contrario, aumentará el apetito por estar allí, actuando como un estímulo subliminal tal como la repetición de los avisos publicitarios en ambientes atractivos estimula el deseo de acceder a aquello que se vende en imagen. Pero al visitar el museo el usuario del software estará en mejores condiciones para tener una experiencia significativa; su visita será más prolongada y los resultados más profundos. Le ayudarán en el proceso los conocimientos que adquirió cuando de manera práctica diseñó una o varias formas de acceso al pasado remoto; la memoria práctica surgida de un pensamiento aplicado a casos específicos facilitará la búsqueda de aquello que conoce parcialmente. Las preguntas serán mejor fundamentadas y muy probablemente el ámbito de discusión se ampliará considerablemente al existir muchas más personas interesadas verdaderamente en los temas arqueológicos.

La popularización del tema arqueológico no significa vulgarización ${ }^{6}$, sino amplificación de la percepción de los valores culturales que encierra. La idea es elevar los estándares, no disminuirlos, estimular el pensamiento, no imponer nociones paternalmente (Longworth 1994: 6). La arqueología tradicional tanto como la museología han sido repensadas y reorientadas no solamente en aspectos epistemológicos, también en su comunicabilidad. El frescor del análisis postmoderno ha contribuido, entre otros aportes, con la aceptación del otro en segunda y tercera persona, desde un punto de vista disciplinario del mismo modo que de la intercomunicación con públicos no especializados. Por su parte, la museología crea espacios propicios para estos diálogos, contribuyendo con el mejor conocimiento de los escenarios y contenidos culturales, actores e interlocutores.

La interpretación arqueológica de los bienes culturales es una mirada disciplinaria desde el interior del museo hacia sus colecciones; la interpretación de la educación de museo es una mirada interdisciplinaria desde el museo hacia afuera, hacia los visitantes y la interpretación que ellos puedan conformar con los elementos que el museo ofrece. Mientras el arqueólogo investiga las colecciones del museo y las sociedades que las produjeron, el educador de museo investiga al público que recibe estos mensajes tanto como los medios más favorables para que la narración científica se con- 
vierta en conocimiento significativo entre los receptores, objetivo de la comunicación. Trabajar con seres humanos implica aspectos éticos importantes, entre otros, fomentar actitudes positivas hacia el aprecio del entorno cultural y el respeto interétnico. Diseñar métodos y estrategias para este fin es un proceso de líneas abiertas basado en fuentes científicas. Este es tan solo un ejemplo.

\section{Referencias Citadas}

AAM [American Association of Museums]

1990 Museum Accreditation: A Handbook for the Institution. AAM, Washington D.C.

Allison, M.J., G. Focacci; B. Arriaza, V. Standen; M. Rivera y

J.M. Lowenstein

1984 Chinchorro, momias de preparación complicada: Métodos de momificación. Chungara 13: 155-173.

Aránguiz, $\mathrm{S}$.

1984 Museos de Chile. Diagnóstico. Dirección de Bibliotecas, Archivos y Museos, Ministerio de Educación Pública, Santiago.

Arriaza, B., A. Aufderheide e I. Muñoz

1984 Análisis antropológico físico de la inhumación de Acha 2. En Acha 2 y los Orígenes del Poblamiento Humano en Arica, editado por I. Muñoz, B. Arriaza y A. Aufderheide, pp. 47-64. Ediciones Universidad de Tarapacá, Arica.

Arriaza, B.

1995 Beyond Death. The Chinchorro Mummies of Ancient Chile. Smithsonian Institution Press, Washington D.C.

Córdova-González, J., Y. Ossandón, J. Bernal y N. Álvarez 2000 Aplicación de multimedios para la enseñanza en museos. Experiencia vinculada al Museo de Historia Natural de Valparaíso. Manuscrito en poder de los autores.

Córdova-González, J., Y. Ossandón, J. Bernal y N. Álvarez 2000a Aproximación a un pasado arqueológico desde una perspectiva etnográfica. Experiencia en el Museo Regional de la Araucanía. Manuscrito en poder de los autores.

Córdova-González, J., Y. Ossandón, J. Bernal y N. Álvarez 2000b Interacciones con el pasado arqueológico. Una experiencia educativa multimedial. Revista Límite 7: 11-26. Universidad de Tarapacá.

Córdova-González, J., Y. Ossandón, J. Bernal y N. Álvarez 2000c Evaluación de los aprendizajes logrados con la utilización de un software para educación de museo. Revista Facultad de Ingeniería 8: 49-59. Universidad de Tarapacá. Crom, W.

1993 Escenario geográfico del sitio Acha 2. En Acha 2 y los Orígenes del Poblamiento Humano en Arica, editado por I. Muñoz, B. Arriaza y A. Aufderheide, pp. 15-19. Ediciones Universidad de Tarapacá, Arica.

Dauelsberg, $\mathrm{P}$.

1974 Excavaciones arqueológicas en Quiani. Provincia de Tarapacá. Departamento de Arica. Chungara 4: 7-38.

Davidson, D.

1992 Mente, Mundo y Acción. Claves para una Interpretación. Introducción y traducción de C. Moya. Paidós, Barcelona.

Focacci, G.

1974 Excavaciones en el cementerio Playa Miller 7. Arica (Chile). Chungara 3: 24-74.
Fyfe, G. y M. Ross

1999 Decoding the visitor's gaze: rethinking museum visiting. En Theorizing Museums. Representing Identity and Diversity in a Changing World. Editado por S. Macdonald, y G. Fyfe, pp. 127-150. Blackwell, Oxford.

Gardner, H.

1995 Inteligencias Múltiples. La teoría en la Práctica. Paidós, Barcelona.

Hein, G.E.

1998 Learning in the Museum. Routledge, London.

Hein, G.E. y M. Alexander

1998 Museums Places of Learning. AAM, Washington D.C.

Hooper-Greenhill, E.

1988a The Museum: The Socio-Historical Articulations of Knowledge and Things. Doctoral Thesis, Department of Sociology of Education, Institute of Education, University of London.

Hooper-Greenhill, E.

1988b Counting visitors or visitors who count? En The Museum Time Machine. Putting Cultures on Display, editado por R. Lumley, pp. 213-232. Comedia/Routledge, London.

Hooper-Greenhill, E.

1989 The museum in the disciplinary society. En Museum Studies in Material Culture, editado por S.M. Pearce, pp. 61-72. Leicester University Press, Leicester.

Hooper-Greenhill, E.

1991 Museum and Gallery Education. Leicester University Press, Leicester.

Hooper-Greenhill, E.

1992 Museums and the Shaping of Knowledge. Routledge, London.

Hooper-Greenhill, E.

1994a Museum and their Visitors. Routledge, London.

Hooper-Greenhill, E.

1994b Museums and galleries and their audiences: a literature review. En Museums and the Appropriation of Culture, editado por S.M. Pearce, pp. 229-233. The Athlone Press, London.

Hooper-Greenhill, E.

1997 Towards plural perspectives. En Cultural Diversity. Developing Museum Audiences in Britain, editado por E. Hooper-Greenhill, pp. 1-11. Leicester University Press, Leicester.

Hooper-Greenhill, E., editor

1999a The Educational Role of the Museum. Routledge, London.

Hooper-Greenhill, E.

1999b Museums and cultural diversity in contemporary Britain. En The Educational Role of the Museum, editado por E. Hooper-Greenhill, pp. 288-293. Routledge, London. 
Hooper-Greenhill, E.

2000 Museums and the Interpretation of Visual Culture. London, Routledge.

Hooper-Greenhill, E. y T. Moussouri

2000 Visitors' Interpretive Strategies at Wolverhampton Art Gallery. $1^{\text {st }}$ Report. RCMG (Research Centre for Museums and Galleries), Leicester.

Longworth, I.

1993 Museum and archaeology. Coping with the chimaera. Museum archaeology in Europe. Proceedings of a Conference held at The British Museum, editado por D. Gaimster, pp. 1-8. Oxbow Books, Oxford.

Lyotard, J-F.

1994 La Condición Postmoderna. Cátedra S.A., Madrid.

Magendzo, A., P. Donoso y M.T. Rodas.

1997 Los Objetivos Transversales de la Educación. Editorial Universitaria, Santiago.

Merriman, N.

1989a The social basis of museum and heritage visiting. En Museum Studies in Material Culture, editado por S.M. Pearce, pp. 153-171. Leicester University Press, Leicester.

Merriman, N.

1989b Museum visiting as a cultural phenomenon. En The

New Museology, editado por P. Vergo, pp. 148-171. Reaktion Books, London.

MINEDUC [Ministerio de Educación Pública de Chile]

1990 Ley 18.962, Ley Orgánica Constitucional de Enseñanza, LOCE. Santiago, Chile.

\section{MINEDUC}

1996 Decreto 40. Objetivos Fundamentales y Contenidos Mínimos de la Enseñanza General Básica. Santiago.

Moliner, M.

1980 Diccionario de Uso del Español. Gredos, Madrid.

Muñoz, I. y J. Chacama

1982 Investigaciones arqueológicas en las poblaciones precerámicas de la costa de Arica. Estudio de las poblaciones costeras del extremo norte de Chile. Documentos de Trabajo 2: 3-97. Universidad de Tarapacá.

Muñoz, I. y J. Chacama

1993 Patrón de asentamiento y cronología de Acha 2. En

Acha 2 y los Orígenes del Poblamiento Humano en Arica, editado por I. Muñoz, B. Arriaza y A. Aufderheide, pp. 21-46. Ediciones Universidad de Tarapacá, Arica.

Roberts, L. C.

1996 From Knowledge to Narrative. Educators and the Changing Museum. Smithsonian Institution Press, Washington D.C.

Schiappacasse, V. y H. Niemeyer

1984 Descripción y análisis interpretativo de un sitio arcaico temprano en la quebrada de Camarones. Publicación Ocasional 41. Museo Nacional de Historia Natural, Santiago.

Standen, V.

1997 Temprana complejidad funeraria en la cultura Chinchorro (norte de Chile). Latin American Antiquity 8: 134156.

Ulloa, L.

1974 Análisis textil del material de los sitios Chinchorro, Quiani, Camarones-15, El Laucho (PLM-7), Faldas del Morro, Alto Ramírez. En aspectos sobre el desarrollo tecnológico en el proceso de agriculturación en el norte prehispano, especialmente Arica (Chile). Chungara 3: 95103.

Ulloa, L.

1982 Evolución de la industria textil prehispana en la zona de Arica. Chungara 8: 97-108.

Valencia Avaria, L., Compilador

1951 Anales de la República. Textos constitucionales de Chile y registro de los ciudadanos que han integrado los poderes ejecutivo y legislativo desde 1810. Primera parte. Editorial Andrés Bello, Santiago.

Vilaxa, A. y J. Corrales

1993 Descripción y comentarios de la fauna malacológica del sitio Acha 2. En Acha 2 y los Orígenes del Poblamiento Humano en Arica, editado por I. Muñoz, B. Arriaza y A. Aufderheide, pp. 81-89. Ediciones Universidad de Tarapacá, Arica.

Vygotsky, L.S.

1978 Mind in Society. The Development of Higher Psychological Processes. Initial translation of A. R. Luria, revisado y editado por M. Cole, V. John-Steiner, S. Scriber y E. Souberman. Harvard University Press, Cambridge, Massachusetts.

\section{Notas}

1 Para ser acreditado como museo, la organización institucional debe ser permanente, no tener fines de lucro, y ser esencialmente educacional, o tener la estética como objetivo [Traducción J. Córdova-González].

2 La investigación sobre los métodos de enseñanza que se aplicaron así como el diseño de los recursos tecnológicos que se emplearon en Yatiqasiña, fue financiada por el Fondo Nacional de Ciencia y Tecnología (FONDECYT 1960683).

3 Este equipo de investigación ha verificado en terreno tanto en Chile como en el extranjero esta aseveración. En Chile durante la presentación del programa educativo en Punta Arenas, Temuco, Santiago, Valparaíso, Viña del Mar, La
Serena. En el extranjero, durante las presentaciones del proyecto en conferencias en Inglaterra, Noruega, Austria, Holanda, Portugal, México, Brasil, Argentina, Ecuador, Estados Unidos de Norteamérica.

4 Parcialmente se refiere a que hay ambientes de trabajo que requieren una base de datos con numerosas imágenes que no pueden quedar en el software distribuido, debido a su peso computacional.

5 Proyecto FONDECYT 1990393, Metodología para la evaluación del aprendizaje en Museos arqueológicos.

6 Considerando la primera acepción de la palabra: no refinado (Moliner 1980: 1556). 